\section{Hormonal and Physiological Responses of Gerbera jamesonii to Flooding Stress}

\author{
C. Olivella, C. Biel, M. Vendrell ${ }^{1}$, and R. Savé \\ Departament de Tecnologia Hortícola, Centre de Cabrils, Institut de Recerca \\ $i$ Tecnologies Agroalimentàries (IRTA), Carretera de Cabrils s $n, 08348$ \\ Cabrils, Catalunya, Spain
}

Additional index words. abscisic acid, cytokinins, flooding, indoleacetic acid, leaves, photosynthesis, root hydraulic resistance, stomatal conductance, transpiration rate, xylem water potential

\begin{abstract}
The effects of flooding (3 days) and recovery (3 days) on leaf gas exchange parameters (stomatal conductance, net photosynthetic assimilation rate, and leaf transpiration rate) were studied in five, 1- year-old gerbera (Gerbera jamesonii Bolus) cultivars under greenhouse conditions. Flooding reduced the measured parameters in all cultivars, which had not recovered 3 days after flooding ceased. A more detailed study was conducted with the 'Beauty' cultivar, in which leaf water potential $\left(\Psi_{\mathrm{w}}\right)$; root hydraulic resistance (Rh); and hormonal concentrations of ABA, IAA, and CK were measured in leaves and roots. Plants were flooded for 2 days, then allowed to recover for 4 days. After 2 days of flooding, $\Psi_{w}$ had decreased and $R h$ had increased. Leaf ABA content increased and IAA and $\mathrm{CK}$ content decreased from the start of flooding and did not change during recovery. In roots a transient increase in root $\mathrm{ABA}$ levels occurred during flooding and a sharp decrease was measured during recovery, which was related to root death. Similar patterns were observed in root $\mathrm{CK}$ concentrations. The IAA concentration in roots remained constant throughout the experiment. The results suggest that ABA and CK may act as signals of flooding stress. Also, the marked intolerance of gerbera to flooding could be a serious barrier to its culture under anaerobic conditions, and hence careful irrigation management is required. Chemical names used: abscisic acid (ABA); indoleacetic acid (IAA); cytokinin (CK).
\end{abstract}

Gerbera is an important cut flower crop in Europe and the United States, and is commonly cultured hydroponically under greenhouse conditions. Physiological effects of light, temperature, and water stress on gerbera productivity have been reported (Lin and French, 1985; Olivella et al., 1998; Savé et al., 1995), but no data are known as to the effects of oxygen deficiency on roots.

The main effect of flooding is a decrease of oxygen availability for the roots, which affects respiration and electron transport (Reid and Wample, 1982). Consequently, physiological and metabolic changes occur, and, in most species, growth is inhibited and roots die. In addition to inhibiting growth, flooding can induce wilting and rolling of leaves, adventitious root formation, and stem hypertrophy. Secondary symptoms of flooding include leaf water deficits and inhibition of photosynthesis

Received for publication 30 July 1999 . Accepted for publication 19 Nov. 1999. We thank Mrs. Anna M. Puerta for her help in analysis of hormones and plant water parameter determinations, and Mr. David Serra for plant maintenance in the greenhouse. This work was partially supported by the UE Research Project EC-DG VI PL-900165. The cost of publishing this paper was defrayed in part by the payment of page charges. Under postal regulations, this paper therefore must be hereby marked advertisement solely to indicate this fact.

${ }^{1}$ Centre d'Investigació i Desenvolupament (CID), Consell Superior d'Investigacions Científiques (CSIC), C/.J.Girona Salgado, 18, 08028 Barcelona, Catalunya, Spain.
(Savé and Serrano, 1986). Many of these changes are associated with alterations in plant hormone concentrations (Davies and Zang, 1991). Under flooding stress, ABA appears to act as a messenger between roots and leaves (Zang and Davies, 1987). Other authors have questioned this model, suggesting that the origin of ABA was not the roots, but the leaves themselves. Reductions in foliar CK concentrations have been reported in plants under flooding stress (Jackson, 1990). These hypotheses have been challenged by other authors, who found that the reduced sap flow was not related to the decrease in the cytokinin concentration in leaves (Smit et al., 1990). Serrano et al. (1988) suggested that flooding increased IAA levels in roots and leaves. Some authors have attributed this to a reduction in IAA transport, because of a deficiency of tion of IAA-oxidase (Reid and Wample, 1982). One of the most characteristic effects of flooding is hypertrophy of the stem, which also occurs in plants treated with an excess of IAA. Like other stresses, including drought stress, flooding causes closing of stomata, turgidity loss, and/or epinasty of leaves (Jackson, 1985).

This study was undertaken to understand the possible role of hormonal balance (ABA, IAA, and CK) in regulating water status in gerbera during flooding, and to evaluate the response of five cultivars of gerbera to this stress in order to optimize the irrigation management of this important horticultural species. oxygen, while others have related it to inhibi-
Plant material. One-year-old plants of five commercial cultivars of gerbera ('Beauty', 'Olivia', 'Delphi', 'Fleur', 'Rozamunde') obtained from in vitro culture were grown in 25$\mathrm{cm}$-diameter pots with a mixture of 4 peat : 1 perlite (v/v) in a greenhouse. The plants were watered daily with nutrient solution $(5 \mathrm{~N}-1.3 \mathrm{P}-$ $4.2 \mathrm{~K})$.

Plants were submitted to flooding for $3 \mathrm{~d}$ followed by $3 \mathrm{~d}$ of recovery. Forty plants of each cultivar were randomly divided into two groups. Twenty control plants were watered daily, and the remaining 20 were immersed in water to $3 \mathrm{~cm}$ above the level of substrate for $3 \mathrm{~d}$, then allowed to recover for $3 \mathrm{~d}$ (Savé and Serrano, 1986). In addition, 10 flooded plants of 'Beauty', which is much appreciated in our country, were used to measure concentrations of endogenous hormones.

Oxygen measurements. Oxygen concentration of the water collected from the substrate by squeezing was measured with a selective Orion ${ }^{\mathrm{TM}}$ electrode (model 97-08; Orion Research, Beverly, Mass.).

Ecophysiological measurements. Leaf gas exchange was measured on seven, intact, topcanopy leaves of similar physiological age. For each cultivar, net $\mathrm{CO}_{2}$ assimilation rate $(P n)$ was measured with a portable system for measuring photosynthesis (ADCLCA-2; Analytical Development Co., U.K). Leaf stomatal conductance (gs) and transpiration rate (TR) were measured with a LI-1600 steady-state porometer (LI-COR, Lincoln, Nebr.). Measurements of 3-d flooding were made in plants still flooded.

In the cultivar Beauty, leaf water potential $\left(\Psi_{w}\right)$ was measured on five leaves with characteristics similar to those described before with a Soilmoisture 3005 pressure chamber (Soilmoisture, Santa Barbara, Calif.). Root hydraulic resistance was also measured in five lateral roots of similar length and age using the same pressure chamber (Savé et al., 1995).

Hormone content. Three plants of each treatment were selected for hormone measurements. Lateral mature roots and leaves with characteristics similar to those described above were excised and immediately immersed in liquid $\mathrm{N}$, then stored at $-80^{\circ} \mathrm{C}$ until use. Each plant was a replicate. ABA, IAA, and zeatin plus zeatin riboside $(Z+Z R)$ were extracted and measured using high-performance liquid chromatography (HPLC) and enzyme-linked immunosorbent assay (ELISA), as described previously (Olivella, 1996; Olivella et al., 1998; Savé et al., 1995). Briefly, $0.2 \mathrm{~g}$ dried leaves were immersed in $10 \mathrm{~mL}$ of the $\mathrm{MeOH} /$ $\mathrm{H}_{2} \mathrm{O}, \mathrm{pH} 3$, for $16 \mathrm{~h} \mathrm{a} 4{ }^{\circ} \mathrm{C}$ in the dark. After centrifugation and evaporation of the organic phase, two different purification procedures were used. For ABA and IAA, the $\mathrm{pH}$ of the extract was adjusted to 8.5 with a half-saturated solution of $\mathrm{NaHCO}_{3}$, and pigments were removed with two $2 \times 5$-mL washes with ethyl acetate. The organic phase was discarded and the $\mathrm{pH}$ of aqueous phase was adjusted to 2.5 with $1 \mathrm{~N} \mathrm{HCl}$. The aqueous phase was then charged on a $\mathrm{C}_{18}$ solid-phase extraction col- 
umn. ABA and IAA were eluted with $5 \mathrm{~mL}$ of diethylether and the ethereal solution was evaporated to dryness. For $\mathrm{Z}+\mathrm{ZR}, \mathrm{pH}$ of the extract was adjusted to 2.5 with $1 \mathrm{~N} \mathrm{HCl}$ and pigments were extracted by washing twice with $5 \mathrm{~mL}$ of diethyl ether. The remaining solvent was evaporated. The residues were resuspended in diethyl ether and methylated with diazomethane.

After drying, the two residues, containing $\mathrm{ABA}$ and IAA, and Z+ZR, respectively, were dissolved in $200 \mu \mathrm{L}$ of the extractant solution and subjected to HPLC. For ABA and IAA separation a $\mathrm{MeOH} / \mathrm{H}_{2} \mathrm{O}(50: 50)$ eluent was used. For Z+ZR elution the eluent was $\mathrm{MeOH} /$ $\mathrm{H}_{2} \mathrm{O}$ (30:50). The three fractions were evaporated to dryness. Estimation of recovery was made by comparison with standard solutions of each hormone.

ELISA measurements were made by a Ephyscience $^{\mathrm{TM}}$ kit from Mayodly and Spindler (Paris, France). Specific monoclonal antibodies were used for ABAMe, IAAMe, and Z+ZR. The procedure was an indirect competition ELISA with a complex protein-hormone bound to the walls of the wells. Residues were resuspended in $500 \mu \mathrm{L}$ of phosphate buffer (PBS) and $100 \mu \mathrm{L}$ plus the specific antibody were left in darkness for $2 \mathrm{~h}$ at $4{ }^{\circ} \mathrm{C}$. The wells were washed and an antimouse goat antibody complexed with peroxidase was added. The hormone bound to the walls was revealed spectrophotometrically at $405 \mathrm{~nm}$ with $2,2^{\prime}$ azino-bis (3-acetic acid) (ABTS). Calculations were made by reference to a calibration curve. The same measurement was made in four wells (replicates).

In another experiment, we measured $\mathrm{ABA}$, IAA, and $\mathrm{Z}+\mathrm{ZR}$ content in adult plants of gerbera cultivars over $10 \mathrm{~d}$ under greenhouse conditions. No significant changes were observed (Olivella, 1996).

\section{Results}

Oxygen concentration (Fig. 1). Oxygen concentration in the water fell after the first day of flooding. On the third day, it reached its lowest value, with clearly anoxic conditions. During recovery, after the substrate had been rewatered, the oxygen concentration rose to the initial values.

Plant water relationships (Fig. 2). The patterns observed in control plants were similar in all cultivars; the differences among them were attributable to small changes in environment, and in morphology and orientation of leaves during measurements. After $1 \mathrm{~d}$ of flooding, gs, TR, and $P n$ of all cultivars were significantly lower than those of the control plants. The stress produced significant changes in plant water parameters during the following days, and their values fell nearly $20 \%$ with respect to the control plants. The measured parameters did not reach the initial values during recovery.

In the cultivar Beauty, water potential did not change during the first $24 \mathrm{~h}$ of stress (Fig. 3 ), but leaves retained their water status and turgidity (Jackson, 1991). Stomatal conductance and transpiration decreased significantly

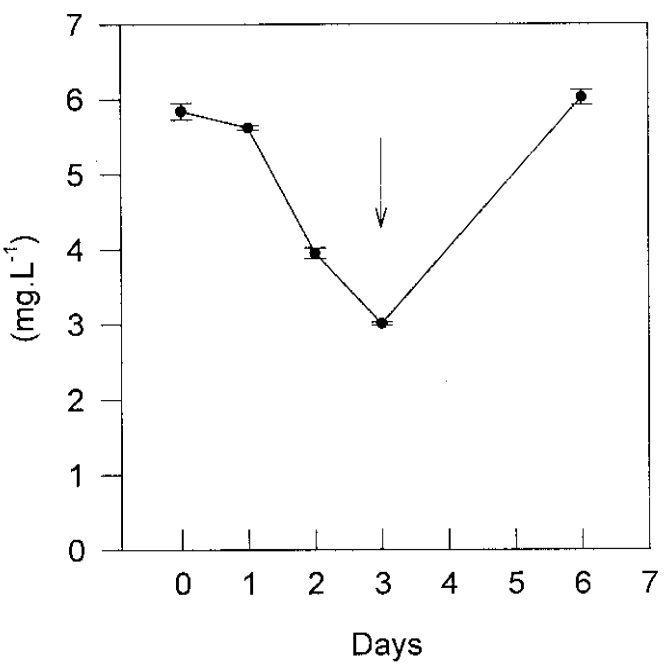

Fig. 1. Change in oxygen concentration of the aqueous phase of the substrate influenced by flooding. Each bar indicates the standard deviation for three replicates. The arrow indicates the beginning of the recovery from flooding stress.
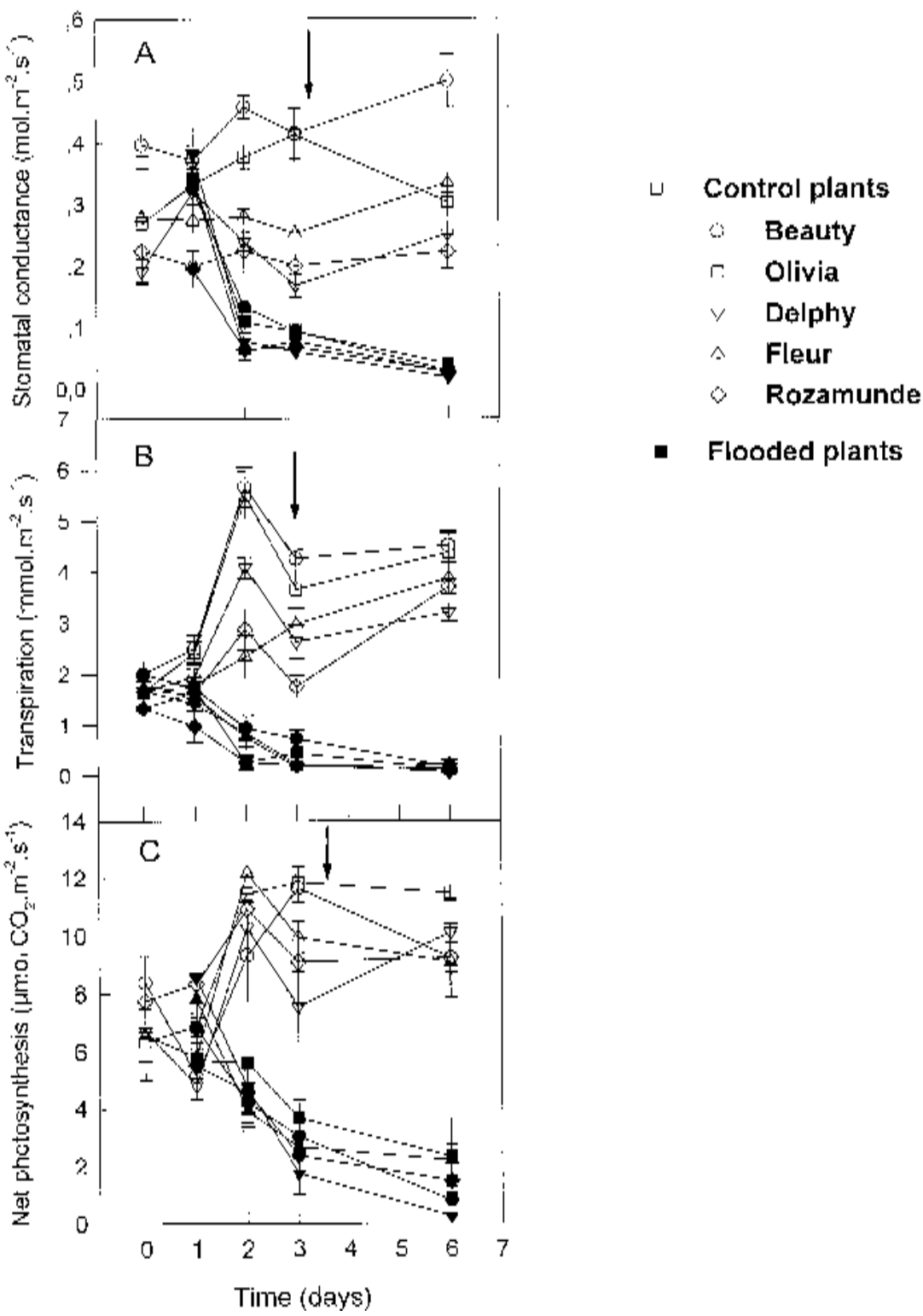

Fig. 2. (A) Stomatal conductance, (B) transpiration rate, and (C) net photosynthesis of five plants of gerbera cultivars subjected to a cycle of flooding. Each bar indicates the standard deviation for seven replicates. The arrow indicates the beginning of the recovery from flooding stress. 
(Fig. 2), but the root hydraulic resistance did not change (Fig. 3) during the first $24 \mathrm{~h}$ of stress. After $72 \mathrm{~h}$, the water potential in 'Beauty' had fallen $50 \%$, and the root hydraulic resistance had increased $1500 \%$ relative to the controls. During recovery, neither the xylem water potential nor the root hydraulic resistance regained the control values (Fig. 3). Similarly, the gas exchange parameters studied did not reattain the initial values.

Hormone content. Leaf ABA concentration in 'Beauty' increased only slightly after the first day of flooding (Fig. 4) but was 10 times the initial value after $3 \mathrm{~d}$. In the recovery period ABA did not decrease. There was a strong negative correlation between leaf ABA concentration and stomatal conductance $\left(r^{2}=\right.$ $0.953, P \leq 0.01)$. Foliar CK concentrations remained constant during the first day of anoxia, but declined dramatically the second day, coinciding with the decrease in stomatal conductance. A significant positive correlation between the CK concentrations in leaves and the stomatal conductance was established $\left(r^{2}=0.962, P \leq 0.01\right)$. The IAA concentration in leaves decreased significantly during the first $2 \mathrm{~d}$ of flooding, but remained unchanged thereafter, including during the recovery period. This decrease in IAA coincided with the beginning of the decrease in stomatal conductance. Root ABA concentration did not change during the first day of flooding, but increased 4-fold during the second day. After $3 \mathrm{~d}$ it had fallen to about twice the initial values. During the recovery period, the root $\mathrm{ABA}$ concentration fell below the initial values, which may be attributable to root death. During the assay we observed dead roots in flooded plants, but did not attempt to quantify this. The concentration of root cytokinins did not increase significantly during the first day of flooding, remained constant during the second day, and decreased to the initial values the third day; recovery did not produce any other change. Root IAA concentration did not change significantly during the flooding cycle and recovery. There was a negative and significant correlation between stomatal conductance and leaf hormonal relations, as well as leaf ABA : IAA $\left(r^{2}=0.914, P \leq 0.05\right)$ and ABA : CK $\left(r^{2}=\right.$ $0.863, P \leq 0.05)$ ratios.

\section{Discussion}

The partial stomatal closure measured during the first $24 \mathrm{~h}$ of flooding can occur without a decrease in leaf turgor. Because it is not a simple passive response to water deficits resulting from high root resistance, it must be associated with other processes, as hormonal concentrations and their relationships. Changes in leaf water parameters ( $g s, T R, \Psi_{\mathrm{w}}$ ) and net photosynthesis $(P n)$ occurred during flooding to regulate water loss, and to avoid injuries caused by a decrease in the availability of water. The dramatic increase in root hydraulic resistance observed could be attributable to injuries at the membrane level (Savé and Serrano, 1986).

The rise in leaf ABA content may be responsible for the observed regulation in stomatal

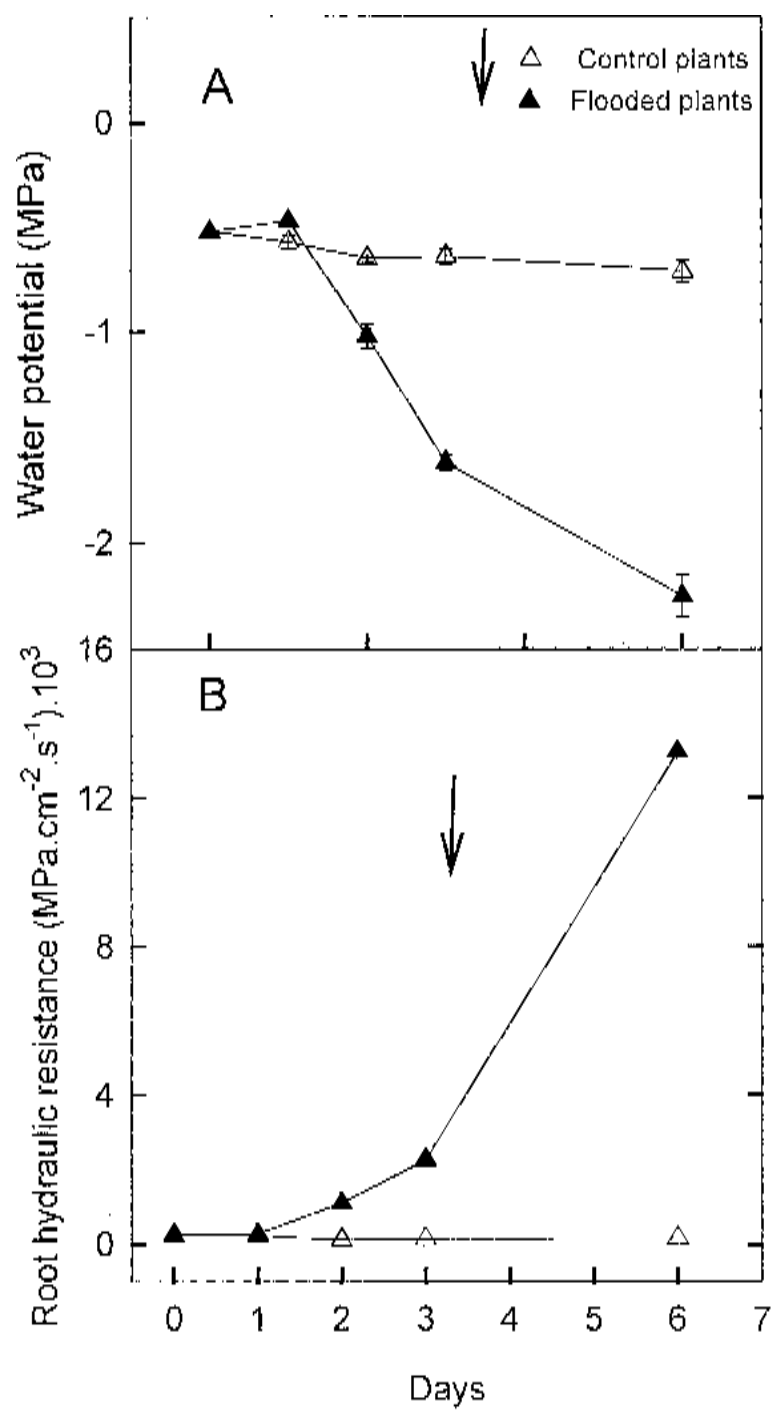

Fig. 3. (A) Water potential and (B) root hydraulic resistance in the gerbera cultivar Beauty, subjected to a flooding cycle. Each bar indicates the standard deviation for five replicates. The arrow indicates the beginning of the recovery from flooding stress.

conductance and transpiration (Castonguay et al., 1993). IAA and CK may counteract ABA by promoting the opening of stomata. The decreases observed in their concentrations in leaves could be related to the closing of stomata and, consequently, to reduced stomatal conductance and transpiration (Mansfield and McAinsh, 1995). Significant and negative correlations were found between $\mathrm{ABA}$ and IAA concentrations and between ABA and CK levels.

According to Jackson and Drew (1984), ABA acts as a signal between roots, the perceptors of the stress, and leaves. This hypothesis could justify the transient increases detected in root $\mathrm{ABA}$ content; $\mathrm{ABA}$ would be transported to the leaves later, and consequently a decrease in root ABA would occur. Moreover, if the roots were seriously damaged they would be unable to synthesize ABA.

Roots are the principal site of synthesis of cytokinins (specifically the terminal meristem) and hypoxia may reduce such synthesis. Also hypoxia reduces cytokinin transport through the xylem (Neuman et al. 1990). This could explain the initial increase in root cytokinins.
Associated with root hypoxia is adventitious root formation. Wample and Reid (1979) have suggested that simultaneous application of auxin and ethylene may promote root formation in sunflower (Helianthus annuum L.) hypocotyls subjected to flooding. However, they were unable to induce adventitious root formation by exogenous application of auxin.

We conclude that gerbera plants responded to flooding by regulating plant water parameters at the canopy level. Hormonal balance probably plays a major role in regulating stomatal movements. At the root level, hypoxia appeared to cause severe injury in the membrane and tissues, and the initial values were not reattained after a period of recovery. The results may indicate that $\mathrm{ABA}$ and $\mathrm{CK}$ act as signals of flooding stress.

The markedly low tolerance of gerbera plants to flooding was indicated by physiological and growth parameters. These results indicate that irrigation management of this species is complicated. Thus a good combination of physical substrate properties and irrigation scheduling is required. Substrates must have high porosity to allow good drainage and 


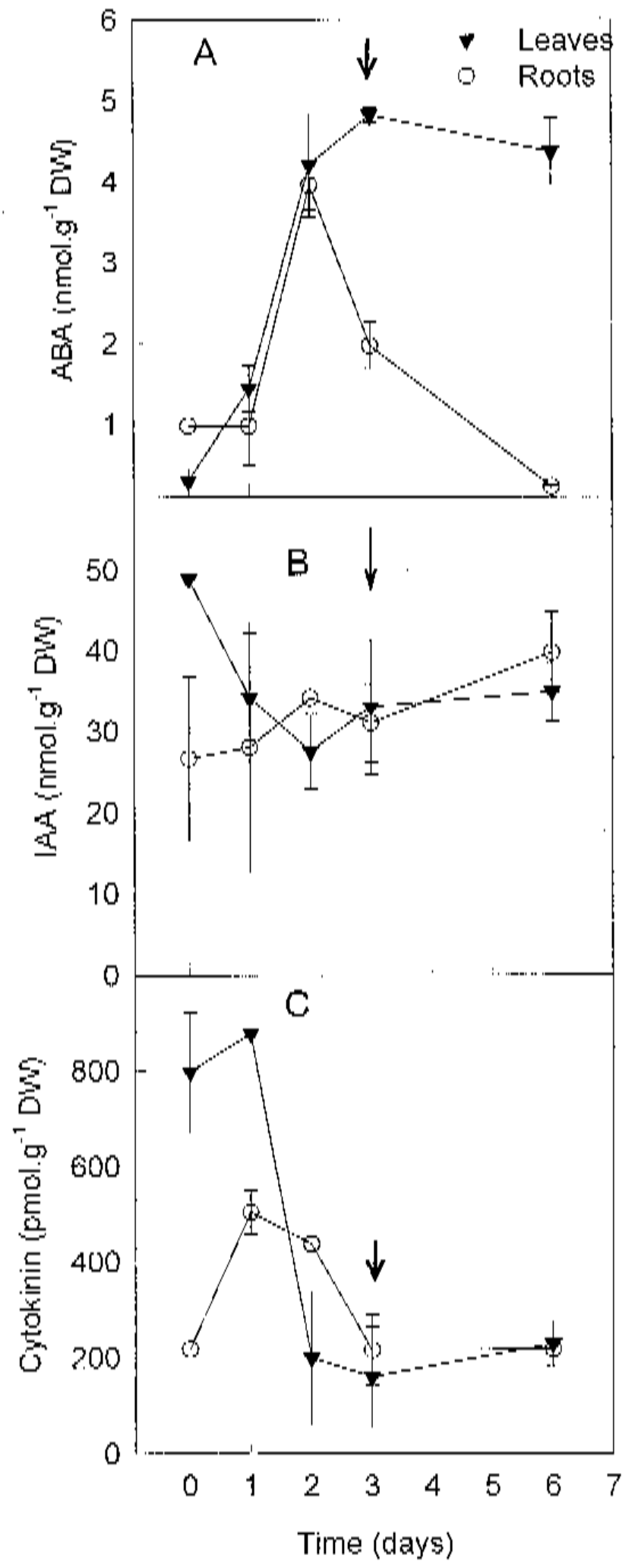

Fig. 4. The concentrations of (A) ABA, (B) IAA, and (C) cytokinin in the gerbera cultivar Beauty, subjected to a flooding cycle. Each bar indicates the standard deviation for three replicates. The arrow indicates the beginning of the recovery from flooding stress.

maintain high oxygen levels. Irrigation must be applied in short pulses in order to maintain the oxygen content of the substrate. Under Mediterranean conditions additional requirements are needed, considering the scarcity of water. the regulation of growth and development of plants in drying soil. Annu. Rev. Plant Physiol. Plant Mol. Biol. 42:55-76.

Jackson, M.B. 1985. Ethylene and responses of plants to soil waterlogging and submergence. Annu. Rev. Plant Physiol. 36:145-174.

Jackson, M.B. 1990. Communication between the roots and shoots of flooded plants. Importance of root-to-shoot communication in the responses to environmental stress. Brit. Soc. Plant Growth Regulat. Monograph 21:115-133.

Jackson, M.B. 1991. Regulation of water relationships in flooded plants by ABA from leaves, roots and xylem sap, p. 217-226. In: W.J. Davies and H.G. Jones (eds.). Abscisic acid, physiology and biochemistry. BIOS Sci., Oxford, U.K.

Jackson, M.B. and M.C. Drew. 1984. Effects of flooding on growth and metabolism of herbaceous plants, p. 47-127. In: T.T. Kozlowsky (ed.). Flooding and plant growth. Physiological ecology. Academic, New York.

Lin, W.C. and C.J. French. 1985. Effect of supplementary lighting and soil warming on flowering of three gerbera cultivars. HortScience 20:271273.

Mansfield, T.A. and M.R. McAinsh. 1995. Hormones as regulators of water balance, p. 598616. In: P.J. Davies (ed.). Plant hormones and their role in plant growth and development. Martinus Nijhoff, Dordrecht, The Netherlands.

Neuman, D.S., S.B. Rood, and B.A. Smit. 1990. Does cytokinin transport from root-to-shoot in the xylem sap regulate leaf responses to root hypoxia? J. Expt. Bot. 41:1325-1333.

Olivella, C. 1996. Aspectes analítics i estudi del balanç hormonal de les plantes de gerbera sotmeses a estressos abiòtics. Tesi Doctoral. Univ. de Barcelona.

Olivella, C., M. Vendrell, and R. Savé. 1998. Abscisic acid and ethylene content in Gerbera jamesonii plants submitted to drought and rewatering. Biol. Plant. 4:613-616.

Reid, D.M. and R.L. Wample. 1982. Water relations and plant hormones, p. 513-578. In: R.P. Pharis and D.M. Reid (eds.). Hormonal regulation of development. III. Role of environmental factors. Encyclop. of Plant Physiol. (N.S.) vol. 11. Springer-Verlag, Berlin.

Savé, R., J. Peñuelas, I. Filella, and C. Olivella. 1995. Water relations, hormonal level, and spectral reflectance of Gerbera jamesonii Bolus subjected to chilling stress. J. Amer. Soc. Hort. Sci. 120:515-519.

Savé, R. and L. Serrano. 1986. Some physiological and growth responses of kiwifruit (Actinidia chinensis) to flooding. Physiol. Plant. 66:75-78.

Serrano, L., R. Savé, and O. Marfà. 1988. Effects of waterlogging on rooting capacity of Hydrangea macrophylla L. Scientia Hort. 36:119-124.

Smit, B.A, D.S. Neuman and M.L. Stachowiak. 1990. Root hypoxia reduces leaf growth. Role of factors in the transpiration stream. Plant Physiol. 92:1021-1028.

Wample, R.L. and D.M. Reid. 1979. The role of endogenous auxins and ethylene in the formation of adventitious roots and hypocotyl hypertrophy in flooded sunflower plants (Helianthus апnuиs). Physiol. Plant. 45: 219-226.

Zhang, J. and W.J. Davies. 1987. ABA in roots and leaves of flooded plants. J. Expt. Bot. 38: 649659. 